\title{
STRATEGI BISNIS DALAM PENGEMBANGAN PRODUK KEMASAN KARTON BERGELOMBANG MIKRO FLUTE DI PT TEMPRINA MEDIA GRAFIKA
}

\author{
Libert Hutahaean \\ Universitas Airlangga \\ lhutahaean@gmail.com \\ Basuki \\ Universitas Airlangga \\ basuki@ feb.unair.ac.id

\section{Abstract}

Perusahaan menyusun strategi bisnis untuk mencapai tujuan perusahaan yaitu pertumbuhan yang berkelanjutan salah satunya melalui pengembangan produk. Strategi bisnis yang berhasil itu harus relevan dengan lingkungan eksternal dan lingkungan internal Perusahaan. Sedangkan perencanaan pengembangan produk harus dapat memenuhi permintaan pelanggan. Penelitian studi kasus di PT TMG bertujuan menyusun rancangan alternatif strategi bisnis pengembangan produk kemasan karton bergelombang mikro flute menggunakan analisis SWOT dengan teknik analytical network process (ANP). Sedangkan pengembangan konsep produk kemasan karton bergelombang mikro flute menggunakan metode Quality Function Deployment (QFD). Hasil penelitian menunjukan prioritas alternatif rancangan strategi bisnis dan rencana disain atau kebutuhan teknis pengembangan produk kemasan mikro flute.

Keywords:ANP-SWOT; Strategi bisnis; Mikro flute; Pengembangan Produk; QFD

\section{PENDAHULUAN}

Permintaan produk kemasan meningkat seiring dengan pertumbuhan penduduk dunia, perkembangan ekonomi dan perubahan tren permintaan konsumen. Demikian juga jumlah penduduk Indonesia yang pada tahun 2015 sekitar 238,5 juta jiwa dan hasil sensus tahun 2020 menjadi berjumlah 270 juta jiwa (Badan Pusat Statistik, 2020). Meningkatnya jumlah penduduk Indonesia akan mendorong peningkatan permintaan di beberapa sektor Industri diantaranya makanan \& minuman, fast moving consumer good, produk elektronik dan listrik, material bangunan, otomotif, tekstil dan produk rumah tangga.

Kemasan berbasis kertas terdiri dari dua jenis yaitu kemasan kertas dan kemasan karton bergelombang (corrugated carton). Produk kemasan kertas yang memiliki karakteristik ringan dan mudah didaur ulang, adalah keunggulan kemasan berbasis kertas yang menjadikannya komponen penting dalam kehidupan modern saat ini. Pertumbuhan industri kemasan diproyeksikan berada di kisaran 5\%-6\% dalam 10 
tahun kedepan dimana nilai pasar sekitar Rp 100 triliun pada tahun 2020 (Federasi Pengemasan Indonesia, 12 Desember 2019). Sedangkan untuk kemasan karton bergelombang, berdasarkan informasi dari PICCI (Indonesian Corrugated Cardboard Industries Association), tumbuh sekitar 15\% pada tahun 2018.

PT TMG adalah perusahaan percetakan yang awalnya didirikan untuk melayani jasa percetakan koran. Sebelum tahun 2010, komposisi pendapatan utamanya (60-80\%) dari pendapatan cetak koran. Dengan perkembangan teknologi yang berdampak pada perilaku pembaca koran, saat ini komposisi pendapatan telah bergeser yang didominasi pendapatan cetak buku pelajaran dan umum. Kemudian untuk tujuan pertumbuhan bisnis yang berkelanjutan, sejak tahun 2016 PT TMG melakukan diversifikasi segmen usaha percetakan (offset packaging) kemasan kertas bagian dalam (inner packaging). Komposisi sumber pendapatan PT TMG mengalami perubahan dengan adanya segmen usaha cetak kemasan sebagai berikut:

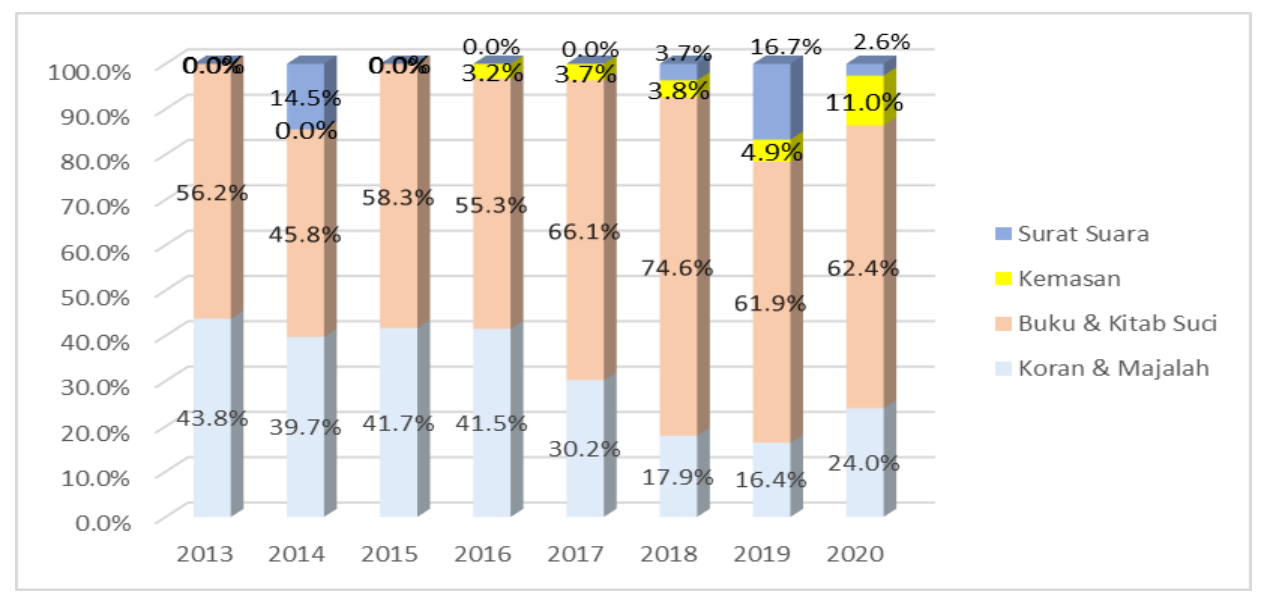

Sumber: Diolah dari laporan Perusahaan

\section{Gambar 1.1 Komposisi Pendapatan PT TMG 2013-2020}

Pada umumnya jenis kertas yang digunakan perusahaan cetak kemasan (packaging) termasuk PT TMG adalah kertas Ivory (full pulp) dan Duplex (daur ulang dicampur dengan pulp) untuk kemasan bagian dalam atau kemasan primer, sedangkan kemasan bagian luar (outer packaging) atau kemasan sekunder terbuat dari kertas karton bergelombang (corrugated).

Berdasarkan informasi PICCI (Indonesian Corrugated Cardboard Industries Association), Industri kertas karton bergelombang di Indonesia sangat kompetitif dan sudah banyak pemain besar yang sudah cukup lama menggeluti pasar tersebut. Tetapi pada umumnya untuk jenis flute $\mathrm{A}, \mathrm{B}$, dan $\mathrm{C}$ sedangkan mikro flute baik 
jenis Flute $\mathrm{E}$ dan $\mathrm{F}$ maupun $\mathrm{N}$ belum banyak perusahaan yang memproduksi jenis tersebut.

Mempertimbangkan tingginya pertumbuhan industri yang membutuhkan kemasan, perubahan perilaku konsumen dan regulasi pemerintah yang mendukung produkproduk yang ramah lingkungan, peluang meningkatnya permintaan pasar kemasan kertas khususnya kemasan kertas karton bergelombang (corrugated carton box) mikro flute menjadi tantangan pengembangan bisnis untuk menopang kelangsungan usaha PT TMG. Sesuai data dan informasi di atas, meningkatnya kebutuhan kemasan merupakan peluang pertumbuhan bisnis meskipun ada ditengah kompetisi yang sangat ketat. Sebagai alternatif selain dari kertas Ivory maupun Duplex, PT TMG berencana mengembangkan bisnis kemasan berbasis kertas karton bergelombang (corrugated carton) micro flute tipe flute $\mathrm{E}, \mathrm{F}$ dan $\mathrm{N}$ sebagai salah satu strategi pertumbuhan di masa yang mendatang.

Berdasarkan latar belakang dan kondisi diatas, peneliti melakukan penelitian bagaimana strategi bisnis dalam pengembangan lini produk baru kemasan kertas bergelombang (Corrugated carton box) jenis Mikro Flute di PT. TMG. Sedangkan tujuan penelitian ini adalah sebagai berikut:

1. Melakukan analisis internal dan lingkungan eksternal Perusahaan serta kajian pengembangan produk baru di PT. TMG.

2. Memberikan rekomendasi rancangan strategi bisnis pengembangan usaha dengan pengembangan produk baru yang direncanakan menjadi sumber pertumbuhan PT. TMG. Perusahaan yang menjadi objek penelitian adalah PT. TMG.

\section{KAJIAN PUSTAKA}

\subsection{ANP-SWOT}

Analisis kekuatan, kelemahan, peluang dan ancaman (SWOT) membantu dalam penyusunan strategi bisnis (Jarzabkowski dkk, 2009). Metode analytical hierarchy process (AHP) mengatasi kekurangan dalam pengukuran dan evaluasi langkahlangkah dalam analisis SWOT (Hill dan Westbrook, 1997). Namun demikian, AHP tidak mengukur kemungkinan ketergantungan antar faktor. Metode AHP memiliki kemampuan untuk menggabungkan yang berbeda-beda jenis kriteria dalam struktur keputusan multi-level untuk mendapatkan skor tunggal untuk setiap alternatif (Saaty, 1980). Metode ini merupakan kerangka kerja yang dirancang untuk mengatasi atau mengurangi subyektifitas, intuisi, rasional, dan irasional ketika keputusan multi-tujuan dan multi-kriteria, dengan atau tanpa kepastian untuk sejumlah alternatif. 
Kemudian Saaty (1996) mengembangkan metode analytical network process (ANP) yaitu perbandingan berpasangan untuk setiap level sehubungan dengan tujuan pemilihan alternatif terbaik. Meskipun teknik AHP menghilangkan kekurangan yang melekat dalam langkah-langkah pengukuran dan evaluasi Analisis SWOT, tidak mengukur kemungkinan ketergantungan antar faktor (Yuksel, 2007). Metode AHP mengasumsikan bahwa faktor-faktor yang disajikan dalam struktur hierarki bersifat independen, namun ini tidak selalu asumsi yang tepat. Ketergantungan yang mungkin di antara faktor-faktor hanya dapat ditentukan sebagai akibat dari analisis lingkungan internal dan eksternal. Kekuatan yang dimiliki perusahaan dapat mempengaruhi dalam memanfaatkan peluangnya dengan baik sehingga memiliki keunggulan bersaing. Hubungan serupa juga ada antara ancaman dan kekuatan. Kemampuan untuk mengatasi atau melawan dampak ancaman bergantung pada kekuatan; perusahaan yang kuat dapat menggunakan kekuatannya untuk menghilangkan atau meminimalkan akibat ancaman yang ada. Hubungan antara kelemahan dan kekuatan suatu perusahaan sedemikian rupa sehingga perusahaan dengan lebih banyak kekuatan mungkin memiliki lebih sedikit kelemahan, dan karenanya akan mampu menghadapi situasi yang timbul dari kelemahan yang ada.

Di antara faktor-faktor strategis, kombinasi dua variabel lainnya dengan kemungkinan saling ketergantungan adalah kelemahan-ancaman dan peluangkelemahan. Dapat dikatakan bahwa organisasi dengan lebih banyak kelemahan daripada mereka saingan lebih rentan terhadap ancaman. Dengan demikian, organisasi harus mempertimbangkan hubungan diantara ancaman dan kelemahan saat menetapkan strategi. Demikian pula, perusahaan dengan kelemahannya mungkin lebih sulit untuk memanfaatkan peluangnya dengan baik. Sedangkan bagi sebuah perusahaan bisa mendapatkan keuntungan dari peluang jika memiliki aset dan kemampuan yang memadai, tetapi jika tidak, peluang tersebut muncul dari lingkungan eksternal menjadi tidak berguna (Yuksel, 2007). Faktor SWOT dapat tidak independen satu dengan lain, tetapi mungkin ada hubungan antara beberapa faktor. Karena bobot faktor secara tradisional dihitung dengan mengasumsikan bahwa faktor independen, ada kemungkinan bahwa bobot yang dihitung dengan memasukkan hubungan dependen bisa berbeda. Perubahan yang mungkin terjadi pada bobot faktor dapat mengubah prioritas strategi alternatif, dan ini perubahan, pada gilirannya, dapat mempengaruhi strategi yang dipilih. Oleh karena itu, perlu dilakukan analisis yang mengukur dan memperhitungkan kemungkinan ketergantungan di antara faktor-faktor dalam analisis SWOT. ANP terdiri dari empat langkah utama (Yuksel, 2007) sebagai berikut:

\section{Konstruksi model dan Penataan masalah}

Masalah harus dinyatakan dengan jelas dan diuraikan menjadi sistem yang rasional, seperti jaringan. Struktur jaringan ini dapat diperoleh oleh para pengambil keputusan atau pemimpin melalui brainstorming atau metode lain yang sesuai. 


\section{Matriks perbandingan berpasangan dan vektor prioritas}

Mirip dengan perbandingan yang dilakukan di AHP elemen keputusan, berpasangan di setiap kluster dibandingkan sehubungan dengan kepentingannya terhadap kriteria kontrol mereka. Kluster itu sendiri juga dibandingkan secara berpasangan sehubungan dengan kontribusinya terhadap tujuan. Pengambil keputusan diminta untuk menanggapi serangkaian perbandingan berpasangan dari dua elemen atau dua kelompok untuk dievaluasi dalam kaitannya dengan kontribusinya pada kriteria tingkat atas tertentu mereka. Selain itu, saling ketergantungan antar elemen kluster juga harus diperiksa secara berpasangan; pengaruh setiap elemen pada elemen lain dapat diwakili oleh eigen vektor. Ini mencerminkan jawaban atas dua pertanyaan: mana dari dua elemen yang lebih penting sehubungan dengan kriteria tingkat yang lebih tinggi, dan seberapa kuat direpresentasikan dengan skala 1-9 Saaty. Seperti dengan AHP, perbandingan berpasangan dalam ANP dilakukan dalam kerangka matriks, dan vektor prioritas lokal dapat diturunkan sebagai perkiraan kepentingan relatif yang terkait dengan elemen (atau kluster) yang dibandingkan dengan menyelesaikan persamaan berikut: $\mathrm{A} \mathrm{x} \mathrm{w}=\chi_{\max } \mathrm{x} \mathrm{w}$ dimana $\mathrm{A}$ adalah matriks perbandingan berpasangan, $\mathrm{w}$ adalah vektor eigen, dan $\chi_{\max }$ adalah nilai eigen terbesar dari $\mathrm{A}$.

\section{Pembentukan Supermatriks:}

Untuk mendapatkan prioritas global dalam sistem dengan pengaruh yang saling bergantung, vektor prioritas lokal dimasukkan ke kolom matriks yang sesuai. Sebagai hasilnya, supermatriks sebenarnya adalah matriks yang dipartisi, di mana setiap segmen matriks mewakili hubungan antara dua kluster dalam suatu sistem. Kluster sistem keputusan menjadi $\mathrm{C}_{\mathrm{k}} ; \mathrm{k}=1,2 \ldots \mathrm{n}$, dan setiap kluster $\mathrm{k}$ memiliki $\mathrm{m}_{\mathrm{k}}$ elemen, dilambangkan dengan $\mathrm{e}_{\mathrm{k} 1} ; \mathrm{e}_{\mathrm{k} 2} \ldots \mathrm{e}_{\mathrm{mk}}$. Vektor prioritas lokal yang diperoleh pada langkah 2 di atas dikelompokkan dan ditempatkan pada posisi yang sesuai dalam supermatrix berdasarkan aliran pengaruh dari satu kluster ke kluster lain, atau dari kluster ke kluster itu sendiri, seperti dalam loop.

\section{Pemilihan alternatif terbaik}

Jika supermatriks yang dibentuk pada langkah 3 mencakup seluruh jaringan, maka bobot prioritas dari alternatif dapat ditemukan pada kolom alternatif di supermatrix yang dinormalisasi. Di sisi lain, jika supermatrix hanya terdiri dari kluster yang saling terkait, tambahan perhitungan harus dilakukan untuk mendapatkan prioritas keseluruhan dari alternatif. Alternatifnya dengan prioritas keseluruhan terbesar harus dipilih, karena ini adalah alternatif terbaik yang ditentukan oleh perhitungan dilakukan dengan menggunakan operasi matriks.

Model hierarki dan jaringan yang digunakan dalam penelitian ini untuk analisis SWOT terdiri dari empat tingkatan. Tingkat pertama adalah strategi terbaik, kriteria 
(faktor SWOT) di tingkat kedua dan sub kriteria (sub faktor SWOT) di tingkat ketiga, dan tingkat keempat terdiri dari alternatif (strategi alternatif).

\subsection{QFD}

Quality Function Deployment (QFD) adalah salah satu metode untuk mengembangkan produk dalam perencanaan dan implementasi strategi bisnis. Untuk pertama kalinya diperkenalkan oleh Yoji Akao pada tahun 1966. Salah satu definisi yang diberikan oleh Akao, (dikutip oleh Sharma, Rawani, \& Barahate, 2008): "QFD adalah Sebuah metode untuk mengembangkan kualitas desain yang bertujuan untuk memuaskan pelanggan dan kemudian menerjemahkan permintaan pelanggan ke dalam target desain dan poin jaminan kualitas utama untuk digunakan selama fase produksi". QFD adalah teknik sistematis dan analitis untuk memenuhi harapan pelanggan. QFD adalah proses perencanaan untuk menerjemahkan persyaratan pelanggan (suara pelanggan) ke dalam persyaratan teknis yang sesuai untuk setiap tahap pengembangan dan produksi produk (yaitu strategi pemasaran, perencanaan, desain dan rekayasa produk, evaluasi prototipe, pengembangan proses produksi, produksi, penjualan" (Zaim \& Sevkli, 2002). Sedangkan menurut Guinta dan Praizler (1993), QFD adalah alat yang sempurna untuk perencanaan strategis. QFD menyederhanakan berpikir strategik dengan kerangka kerja untuk mengklarifikasi dan mencapai tujuan. Bagi pengambil keputusan, hal itu dapat membantu mengidentifikasi apa saja yang penting dengan menyediakan sebuah sistem logis sebagai pengganti pengambilan keputusan berdasarkan emosi. Jadi QFD merupakan alat yang dapat digunakan untuk perencanaan pengembangan produk maupun untuk perencanaan strategis bisnis perusahaan. Proses QFD terdiri 4 fase atau 4 quality table (Cristiano dkk, 2001)

1. Matriks Perencanaan. Menghubungkan permintaan pelanggan secara kualitatif ke dalam desain independen, terukur, dan karakteristik kualitas produk. Matrik fase ini ini dikenal sebagai Rumah Kualitas (house of quality/HoQ).

2. Matriks Disain. Fase ini menghubungkan antara karakteristik penting produk dan komponen penting dari desain. Hasil dari fase 2 ini adalah memprioritaskan bagian-bagian komponen desain dalam hal kemampuannya untuk memenuhi tingkat kualitas yang diinginkan.

3. Matriks Operasional/Proses. Tahap ini membandingkan karakteristik komponen penting dengan prioritas proses pembuatan/manufaktur dan spesifikasi untuk parameter proses utama yang diterapkan pada fase ke empat.

4. Matriks Pengendalian. Proses utama pembuatan/manufaktur dan parameter terkait diterjemahkan ke dalam instruksi kerja, rencana pengendalian dan tanggapan, dan persyaratan pelatihan yang diperlukan untuk memastikan kualitas pada bagian dan proses utama terpelihara. 
Dalam penelitian ini menggunakan teknik analisis QFD untuk fase 1 untuk menganalisis kebutuhan atau permintaan pelanggan dan menyusun perencanaan disain kualitas produk.

\section{METODE PENELITIAN}

Pendekatan penelitian ini adalah kualitatif deskriptif jenis studi kasus. Penelitian kualitatif yang bersifat deskriptif bertujuan mendeskripsikan fenomena atau peristiwa dari obyek yang diteliti dengan menafsirkan dan menguraikan data yang ada bersamaan dengan situasi yang sedang terjadi. Studi kasus mengacu pada sejarah terdokumentasi tertentu orang, kelompok, organisasi, atau peristiwa. Biasanya, sebuah studi kasus dapat menggambarkan peristiwa tertentu di perusahaan seperti dalam mengambil keputusan atau menghadapi situasi penting, seperti memperkenalkan produk baru atau berurusan dengan beberapa krisis manajemen (Zikmund dkk, 2009). Sedangkan menurut Yin (2014), melakukan penelitian studi kasus merupakan metode yang lebih sering digunakan dalam situasi: 1) Jika pertanyaan dalam penelitian adalah bagaimana dan mengapa, 2) Peneliti sedikit atau tidak ada kontrol atas peristiwa perilaku, 3) Fokus pada fenomena kontemporer.

\subsection{Data dan Sumber Data}

Jenis data yang diperlukan dalam penelitian ini adalah data primer dan data sekunder. Data primer diperoleh dengan melakukan wawancara kepada orang-orang kunci PT TMG untuk mendapatkan gambaran dan kondisi pada objek penelitian sesuai dengan pokok permasalahan yang akan diteliti di dalam penelitian ini. Selain itu wawancara dilakukan kepada direktur perusahaan afiliasi dan tenaga ahli dari Asosiasi Kemasan Indonesia serta para pelanggan saat ini dan pelanggan potensial. Sedangkan data sekunder diperoleh dari data atau dokumen PT TMG, data industri, riset pasar kemasan, studi literatur dan data lain yang terkait dengan penelitian ini.

\subsection{Teknik Pengumpulan Data}

Di awal peneliti melakukan wawancara kepada Direksi PT TMG untuk mendapatkan gambaran awal kondisi pada objek penelitian sesuai dengan pokok permasalahan dalam penelitian ini. Peneliti mengumpulkan data primer dengan melakukan wawancara terstruktur kepada:

1. Direktur dan GM SBU serta manajer PT TMG

2. Direktur ADP (sister company)

3. Asosiasi kemasan Indonesia

4. Pelanggan existing dan pelanggan potensial. Selain itu dilakukan pengiriman kuesioner kepada 30 responden dari pelanggan existing dan pelanggan potensial. 
Sedangkan data sekunder diperoleh dari data atau dokumen PT TMG, data industri, riset pasar kemasan, studi literatur dan data lain yang terkait dengan penelitian ini.

\subsection{Prosedur Analisis Data}

\subsubsection{Metode ANP-SWOT}

Dalam penelitian ini, berikut supermatriks hierarki SWOT yang digunakan:

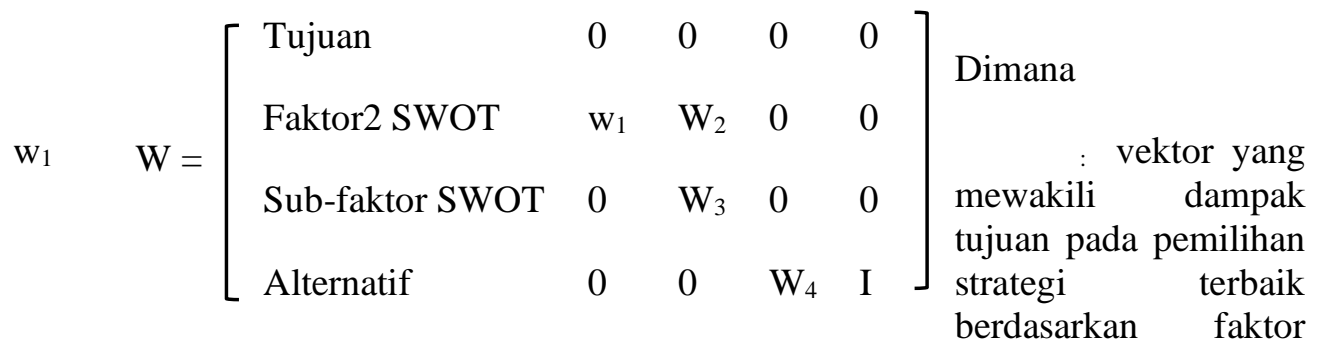

\section{SWOT}

$\mathrm{W}_{2} \quad$ : matriks yang menunjukkan interdependensi internal dari faktor SWOT

$\mathrm{W}_{3} \quad$ : matriks yang menunjukkan pengaruh faktor SWOT terhadap sub-faktor SWOT

$\mathrm{W}_{4} \quad$ : matriks yang mengidentifikasi dampak sub-faktor SWOT pada alternatif

Langkah-langkah teknik analisis data sebagai berikut:

1. Identifikasi sub-faktor SWOT dan tentukan alternatif strategi menurut sub faktor SWOT.

2. Pentingnya setiap kelompok SWOT (kekuatan, kelemahan, peluang dan ancaman) ditentukan dengan menghitung matriks bobot $\mathrm{w}_{1}$, sambil mempertimbangkan situasi di mana tidak ada saling ketergantungan internal di antara faktor-faktor SWOT.

3. Menghitung $\mathrm{W}_{2}$ - matriks ketergantungan bagian dalam dari faktor SWOT, menggunakan skema interdependensi internal diantara masing-masing faktor SWOT.

4. Menentukan prioritas saling ketergantungan dari faktor SWOT (menghitung $\left.\mathbf{w}_{\text {faktor }}=\mathbf{W}_{\mathbf{2}} \times \mathrm{w}_{1}\right)$.

5. Tentukan derajat kepentingan lokal sub-faktor SWOT dengan skala Saaty 1-9.

6. Tentukan derajat kepentingan global sub-faktor SWOT (menghitung $\mathbf{w}_{\text {faktor }} \mathbf{x}$ W sub-faktor(local).

7. Menentukan derajat pentingnya dari alternatif strategi sehubungan dengan setiap sub-faktor SWOT dengan skala Saaty 1-9 (Saaty, 1980) dengan menghitung W4. 
8. Menentukan keseluruhan prioritas dari alternatif strategi, yang mencerminkan keterkaitan di dalam Faktor SWOT dengan menghitung bobot matriks $\mathbf{w}_{\text {alternatif }}$ $=\mathrm{W}_{4} \times \mathrm{X}_{\text {SWOTsub-faktor (global) }}$.

\subsubsection{Metode QFD}

Dalam perencanaan strategi pengembangan produk kemasan dari kertas bergelombang mikro flute, berikut langkah-langkah dalam menyusun matriks HoQ fase 1:

1. Identifikasi pelanggan. Menentukan segmen pelanggan yang memerlukan atau sesuai dengan produk kemasan yang dikembangkan.

2. Menentukan kebutuhan atau permintaan pelanggan dengan wawancara dan kuesioner.

3. Melakukan review atau mengelompokan kebutuhan atau permintaan pelanggan.

4. Merancang kebutuhan teknis produk atas respon kebutuhan pelanggan.

5. Menyusun matriks HoQ.

6. Menentukan hubungan antar komponen dengan ranking pembobotan. Memberikan indikasi tentang hubungan tersebut antara apakah (kebutuhan konsumen) dan bagaimana (teknis atau komponen produk). Pada umumnya, jika ada hubungan antara persyaratan/kebutuhan pelanggan ke-i dan spesifikasi teknis ke-j, di rij sel dari matriks $\mathrm{R}$ simbol yang berbeda akan disisipkan tergantung pada jenis hubungan (kuat, ringan, atau lemah). Tidak adanya simbol menunjukkan kurangnya hubungan antara variabel yang dipertimbangkan.

7. Menyelesaikan matrik HoQ

Dari hasil kedua alat analisis yaitu ANP-SWOT dan QFD yang digunakan untuk mengidentifikasi kondisi internal dan eksternal perusahaan serta permintaan pelanggan atas disain kualitas produk yang dikembangkan, kemudian disusun atau dibuat rancangan strategi bisnis.mendeskripsikan jenis penelitian, cara perolehan data dan analisis data. Dalam metode penelitian, tidak perlu mencatumkan definisi dari uji asumsi yang digunakan.

\section{HASIL DAN PEMBAHASAN}

\subsection{Analisis ANP-SWOT}

\subsubsection{Identifikasi Kekuatan dan Kelemahan}

Berdasarkan hasil wawancara informan yang terdiri dari Direktur Utama dan 1 (satu) Direktur dan para General Manager/Manager PT TMG serta Direktur PT ADP, berikut kekuatan dan kelemahan PT TMG dalam pengembangan produk baru yaitu kemasan mikro flute:

\section{Kekuatan}


- Citra/image Perusahaan yang sudah dikenal di industri percetakan.

- Kuat dalam pendanaan atau permodalan.

- Pemasok utama bahan baku yaitu PT ADP yaitu sister company sebagai produsen kertas daur ulang

- Dalam jaringan/grup usaha besar sehingga lebih cepat kapitalisasi pasar.

Kelemahan

- Belum berpengalaman dalam kemasan kertas bergelombang (corrugated box)

- Kurangnya kompetensi SDM dalam bidang kemasan kertas bergelombang

- Kapasitas dan infrastruktur yang masih kurang dalam industri kemasan kertas.

- Belum memiliki tim atau divisi research \& development (R \& D) yang kuat.

Peluang

- Potensi Besar Pasar Domestik

- Tren Tumbuh Pasar Luar Negeri

- Pertumbuhan UMKM

- Pertumbuhan pasar e-commerce Indonesia

- Isu Ramah Lingkungan

Ancaman

- Ketersediaan bahan baku dengan kualitas bagus dan harga yang kompetitif.

- Sebagai pemain baru, tekanan persaingan yang kuat khususnya dari pemain lama dan besar.

- Daya tawar pelanggan yang preferensinya menggunakan kemasan dari bahan baku kertas Duplex atau Ivory.

- Substitusi produk baik kemasan dari bahan plastik atau bahan lain yang recycle \& reusable maupun biodegradable.

\subsubsection{Alternatif Strategi Menurut Sub Faktor SWOT}

Setelah dilakukan identifikasi faktor internal yaitu kekuatan dan kelemahan dan faktor eksternal yaitu peluang dan ancaman berdasarkan pengumpulan data hasil wawancara dan data industri maupun laporan-laporan perkembangan pasar dari berbagai sumber, serta kajian alternatif strategi yang dilakukan peneliti maka disusun matriks alternatif strategi. Ada empat kelompok alternatif Strategi. Strategi kekuatan atas peluang (SO) yaitu menangkap peluang dengan kekuatan yang ada, strategi kelemahan atas peluang (WO) yaitu memperhitungkan kelemahan untuk mendapatkan manfaat dari peluang yang ada, strategi kekuatan atas ancaman yaitu bagaimana menggunakan kekuatan untuk menghilangkan atau mengurangi ancaman sedangkan strategi kelemahan atas ancaman (WT) yaitu strategi mengurangi dampak ancaman dengan memperhitungkan kelemahan yang dimiliki. Berikut tabel matriks SWOT dan alternatif strategi: 


\begin{tabular}{|c|c|c|}
\hline \multirow[b]{2}{*}{ Faktor Eksternal } & \multicolumn{2}{|c|}{ Faktor Internal } \\
\hline & $\begin{array}{l}\text { Kekuatan (S) } \\
\text { S1: Citra Perusahaan yang sudah } \\
\text { dikenal di industri percetakan } \\
\text { S2: Kuat dalam pendanaan atau } \\
\text { permodalan } \\
\text { S3: Pemasok utama bahan baku } \\
\text { yaitu PT ADP yaitu sister company } \\
\text { sebagai produsen kertas daur ulang } \\
\text { S4: Dalam jaringan/grup usaha } \\
\text { besar sehingga lebih cepat } \\
\text { kapitalisasi pasar }\end{array}$ & $\begin{array}{l}\text { Kelemahan (W) } \\
\text { W1: Belum berpengalaman di } \\
\text { kemasan kertas bergelombang } \\
\text { W2: Kurangnya kompetensi SDM } \\
\text { dalam bidang kemasan kertas } \\
\text { bergelombang } \\
\text { W3: Belum memiliki tim atau } \\
\text { divisi research \& development ( } \\
\text { \& D) yang kuat } \\
\text { W4: Kapasitas dan infrastruktur } \\
\text { yang masih kurang dalam industri } \\
\text { kemasan kertas }\end{array}$ \\
\hline $\begin{array}{l}\quad \text { Peluang (O) } \\
\text { O1: Potensi Besar Pasar Domestik } \\
\text { O2: Pertumbuhan UMKM } \\
\text { O3: Pertumbuhan pasar e- } \\
\text { commerce Indonesia } \\
\text { O4: Tren Tumbuh Pasar Luar } \\
\text { Negeri } \\
\text { O5: Isu Lingkungan }\end{array}$ & $\begin{array}{l}\text { Strategi SO } \\
\text { SO1: Pengembangan internal } \\
\text { dengan investasi agresif dan } \\
\text { strategik } \\
\text { SO2: Sinergi dengan pemasok } \\
\text { bahan baku kertas - PT ADP }\end{array}$ & $\begin{array}{l}\text { Strategi WO } \\
\text { WO1: Investasi (rekrut) SDM } \\
\text { dengan kompetensi tinggi } \\
\text { WO2: Strategic partnership } \\
\text { WO3: Pengembangan model } \\
\text { bisnis mass customization dan } \\
\text { online distribution/digital channel }\end{array}$ \\
\hline $\begin{array}{l}\text { Ancaman (T) } \\
\text { T1: Ketersedian bahan baku dengan } \\
\text { kualitas bagus dan harga yang } \\
\text { kompetitif } \\
\text { T2: Sebagai pemain baru, tekanan } \\
\text { persaingan yang kuat khususnya } \\
\text { dari pemain lama dan besar. } \\
\text { T3: Daya tawar pelanggan yang } \\
\text { preferensinya menggunakan } \\
\text { kemasan dari bahan baku kertas } \\
\text { Duplex atau Ivory. } \\
\text { T4: Substitusi produk baik kemasan } \\
\text { dari bahan plastik atau bahan lain } \\
\text { yang recycle \& reusable maupun } \\
\text { biodegradable }\end{array}$ & \begin{tabular}{l}
\multicolumn{1}{c}{ Strategi ST } \\
ST1: Cost leadership dengan \\
teknologi relevan dan harga bahan \\
baku yang rendah \\
ST2: Strategi marketing fokus pada \\
target pasar
\end{tabular} & $\begin{array}{l}\text { Strategi WT } \\
\text { WT1: Aliansi strategik baik } \\
\text { dengan pemasok maupun media } \\
\text { untuk promosi/kampanye } \\
\text { WT2: Melibatkan aktif existing } \\
\text { kustomer }\end{array}$ \\
\hline
\end{tabular}

\subsubsection{Pemeringkatan Alternatif Strategi}

Menilai prioritas alternatif strategi dengan mempertimbangkan hubungan interdependensi antar faktor-faktor SWOT dengan menghitung bobot matriks $\mathbf{W}_{\text {alternatif }}=\mathbf{W}_{\mathbf{4}} \mathbf{X}$ WSWOTsub-faktor (global) sebagai berikut:

$$
\mathrm{W}_{\text {alternatif }}=\left[\begin{array}{l}
\text { SO1 } \\
\text { SO2 } \\
\text { WO1 } \\
\text { WO2 } \\
\text { WO3 } \\
\text { ST1 } \\
\text { ST2 } \\
\text { WT1 } \\
\text { WT2 }
\end{array}\right]=W_{4} \mathrm{X}_{\text {sub faktor (global) }}=\left[\begin{array}{c}
0.115 \\
0.158 \\
0.121 \\
0.123 \\
0.088 \\
0.113 \\
0.102 \\
0.096 \\
0.084
\end{array}\right]
$$


Berdasarkan analisis ANP-SWOT, 9 (sembilan) alternatif strategi sebagaimana dijelaskan pada tabel 4.1 diatas, diperoleh urutan prioritas alternatif strategi yaitu: SO2 - WO2 - WO1 - SO1 - ST1 - ST2 - WT1 - WO3 - WT2.

\subsection{Analisis QFD}

Berdasarkan review kebutuhan pelanggan yang berasal dari segmen usaha kemasan PT TMG saat ini dan hasil penggalian informasi perkembangan bisnis baik skala kecil sampai dengan skala besar yang memerlukan kemasan berbahan baku kertas yang akan dikembangkan PT TMG yaitu kelompok usaha bidang makanan \& minuman (consumer goods), snack (makanan olahan), kosmetik, farmasi, frozen foods, pakaian dan perlengkapan elektronik diperoleh hasil sebagai berikut:

Tabel 4.13

Nilai Bobot Atribut Permintaan Pelanggan

\begin{tabular}{|c|l|c|c|}
\hline NO & \multicolumn{1}{|c|}{ ATRIBUT PERMINTAAN PELANGGAN } & $\begin{array}{c}\text { Skor } \\
\text { Total }\end{array}$ & Bobot \\
\hline 1 & Kekakuan (stiffness) kemasan kertas bergelombang Mikro Flute & 126 & 4.20 \\
2 & Produk yang dikemas memerlukan kekuatan (stacking performance) dari kemasan Mikro Flute & 133 & 4.43 \\
3 & Kemasan Mikro Flute mampu melindungi produk \& mengemas produk lebih berat atau lebih banyak yang dimuat & 131 & 4.37 \\
4 & Kualitas cetak bagus untuk layer/lapisan permukaan luar kemasan kertas Mikro Flute & 119 & 3.97 \\
5 & Berat kemasan Mikro Flute yang dapat lebih ringan dari bahan Duplex atau Ivory & 122 & 4.07 \\
6 & Harga Mikro Flute yang lebih kompetitif dibandingkan kemasan bahan baku dari Duplex atau Ivory & 135 & 4.50 \\
7 & Kemasan Micro Flute yang mudah dibentuk sesuai disain yang diperlukan & 127 & 4.23 \\
8 & Kemasan Mikro Flute yang lebih tipis dibandingkan bahan baku dari Duplex atau Ivory & 120 & 4.00 \\
9 & Kemasan Mikro Flute dibuat dari bahan baku daur ulang & 121 & 4.03 \\
10 & Kemasan Mikro Flute memberikan nilai daya tarik bagi konsumen \& bagian dari branding produk yang dikemas & 131 & 4.37 \\
\hline
\end{tabular}

Berdasarkan tabel 4.13 di atas, atribut harga yang kompetitif dibandingkan kemasan dari Duplex atau Ivory menjadi pertimbangan utama pelanggan (bobot nilai 4,5), kemudian urutan ke-2 atribut stacking performance (bobot nilai 4,43) dan atribut melindungi produk dan daya tarik bagi konsumen merupakan urutan ke-3 (bobot nilai 4,37).

\subsubsection{Menyusun kebutuhan teknis/disain pengembangan produk atas respon kebutuhan pelanggan}

Prioritas kebutuhan disain/teknis dalam merancang pengembangan produk mikro flute:

1. Material kertas yang kaku dan lentur

Permintaan pelanggan produk kemasan mikro flute yang mempunyai kekakuan bagus memerlukan kertas yang dibentuk bersifat kaku dan lentur. Hal ini akan memudahkan dalam membentuk kemasan yang diperlukan. 
2. Gramatur kertas lebih kecil

Dengan gramatur yang lebih kecil, diharapkan produk mikro flute lebih ringan dan tipis. Hal ini akan membuat harga kemasan mikro flute lebih kompetitif dan biaya transportasi produk yang dikemas dengan mikro flute dapat lebih murah.

3. Permukaan kertas halus dan rata

Dengan permukaan kertas yang halus dan rata menyeluruh akan membuat hasil cetak pada bagian luar kemasan menjadi bagus dan kualitas cetaknya dapat diperbandingkan dengan hasil cetak kemasan yang menggunakan bahan kertas duplex atau yang lainnya.

4. Kaliper yang lebih kecil (thickness) dan jumlah flute yang tepat.

Ketinggian kaliper yang lebih kecil atau lebih tipis dan jumlah flute yang tepat dapat meningkatkan kekuatan stacking mikro flute dan membantu kualitas hasil cetak. Selain itu, dengan kaliper yang lebih kecil dapat mengurangi ruang penyimpanan dan biaya transportasi.

5. Menggunakan bahan baku daur ulang

Produk mikro flute akan menjadi produk hijau (green product) yang ramah lingkungan dengan menggunakan kertas sebagai bahan baku yang berasal dari bahan daur ulang.

6. Mesin yang tepat dan fleksibel.

Karena mikro flute Produk kemasan mikro flute yang dibuat dari kertas dengan gramatur yang lebih rendah, tinggi flute yang lebih rendah dan jumlah flute lebih banyak, maka PT TMG memerlukan investasi mesin yang bagus dan tepat. Hal ini dikarenakan pada umumnya, mesin corrugator yang digunakan saat ini lebih banyak untuk ukuran flute besar (tipe flute A,B,C,D). Selain itu sesuai permintaan pelanggan khususnya dari UMKM, jumlah yang dibutuhkan tidak dalam jumlah besar tetapi dalam jumlah yang lebih sedikit tetapi dapat lebih beragam baik ukuran maupun variasi cetaknya.

7. Double wall corrugated

Kemasan kotak dengan struktur double wall akan memberikan tambahan daya tahan dan kekuatan stacking pada kemasan tersebut. Jumlah dan berat produk serta keperluan keamanan saat pengiriman atau penyimpanan memerlukan struktur board yang lebih dari single wall.

8. Tim disain yang kreatif dan inovatif

Kemasan mikro flute harus memberikan manfaat dan kepuasan pelanggan dari berbagai industri dengan produk yang dihasilkan yang memerlukan kemasan yang aman, nyaman dan sesuai dengan bidang usaha masing-masing pelanggan. Oleh karena itu PT TMG memerlukan tim disain kreatif dan inovatif dalam memberikan solusi kemasan bagi para pelanggan. 


\subsubsection{Penyusunan House of Quality (HoQ)}

Langkah selanjutnya adalah menyusun HoQ berdasarkan hasil penilaian hubungan antar komponen permintaan pelanggan dan kebutuhan disain pengembangan produk. Berikut hasil penyusunan HoQ:

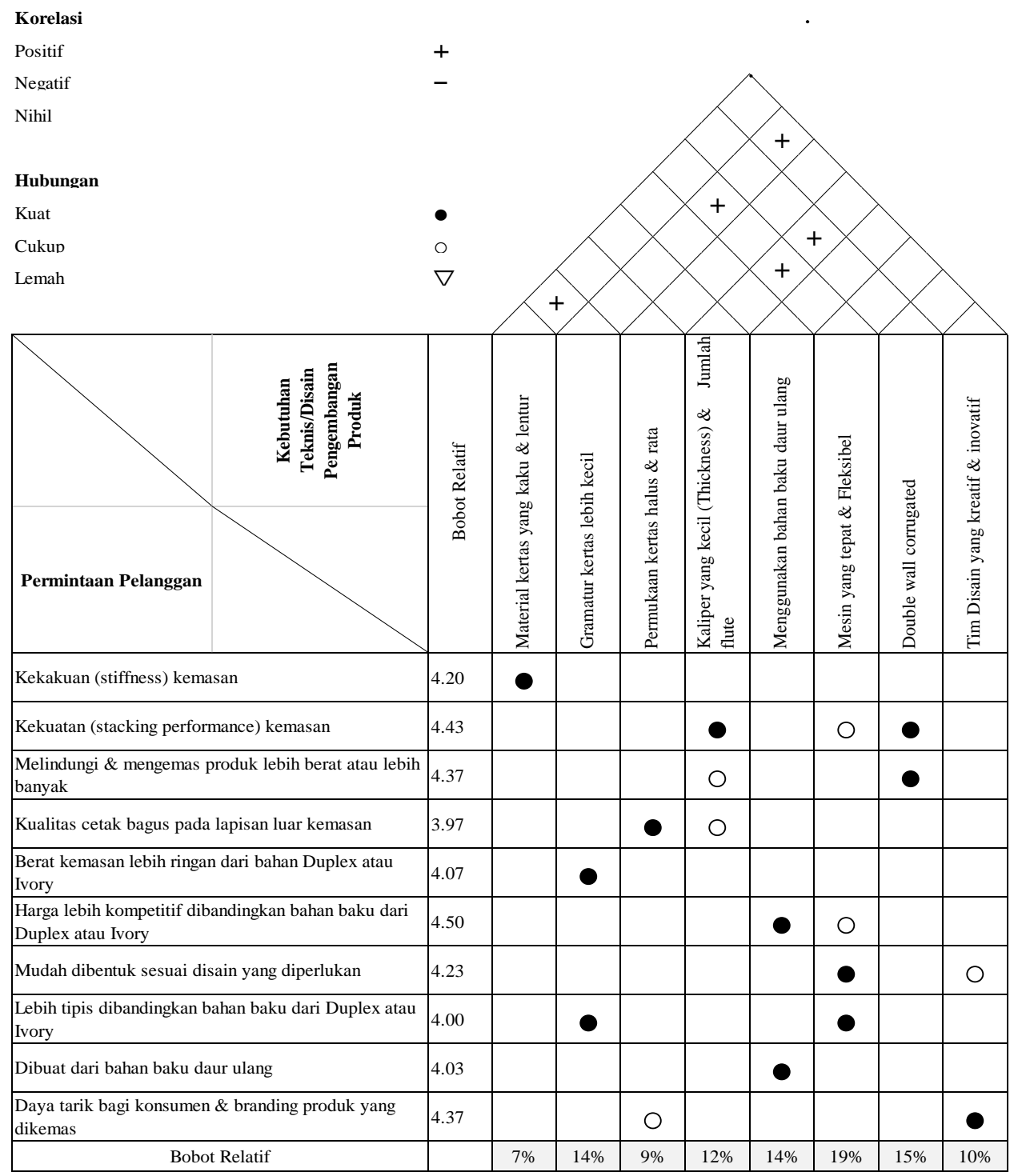




\section{KESIMPULAN}

\subsection{Kesimpulan}

Prioritas alternatif strategi yang dihasilkan dari analisis SWOT-ANP yaitu SO2WO2-WO1-SO1-ST1-ST2-WT1-WO3 - WT2. Dalam rancangan strategi bisnis, dikelompokan dua alternatif strategi bisnis yang merupakan bauran beberapa alternatif strategi dari sembilan alternatif strategi yang diidentifikasi dan dipilih. Alternatif 1 (SO2-ST1-WO1-WO3) merupakan strategi kolaboratif yang fokus pada strategic partnership dengan sister company yang lebih menjamin kepada ketersediaan bahan baku. Sedangkan alternatif 2 (SO1-WO2-ST2-WT1-WO3) lebih fokus pada kemampuan internal untuk melakukan investasi agresif dan strategik serta mengadakan strategic partnership atau aliansi strategis khususnya dengan pemasok utama bahan baku maupun kustomer strategis.

Sedangkan perencanaan pengembangan produk kemasan mikro flute dengan analisis QFD yang bertujuan untuk mengidentifikasi dan menentukan prioritas apa yang menjadi permintaan pelanggan. Dalam studi ini dari sepuluh atribut yang ditentukan, 4 (empat) prioritas permintaan pelanggan adalah harga yang kompetitif, stacking performance yang bagus, melindungi produk lebih baik dan daya tarik bagi konsumen. Bagaimana merespon permintaan pelanggan, PT TMG merencanakan disain atau kebutuhan teknis produk kemasan mikro flute yaitu memilih mesin yang tepat dan fleksibel, fokus pada jenis double wall corrugated dengan kebutuhan gramatur kertas lebih kecil dan menggunakan bahan baku daur ulang.

\subsection{Saran}

Dari hasil penelitian ini dapat dipertimbangkan atau dimanfaatkan sebagai bahan dalam pengambilan keputusan, yaitu:

a. Faktor penting keberhasilan PT TMG masuk ke bisnis kemasan corrugated box yang industrinya sudah mature adalah ketersediaan bahan baku kertas yang dapat dihasilkan oleh PT ADP sebagai sister company yang akan menjadi modal kuat dan keunggulan bersaing di pasar kemasan corrugated box khususnya pasar mikro flute yang berpotensi tumbuh kedepannya.

b. Tahapan lanjutan pengembangan produk kemasan mikro flute menjadi fase krusial untuk bisa berhasil ketika mulai produksi komersial. PT TMG perlu investasi dengan merekrut tenaga yang pengalaman dan kompeten di bidang kemasan corrugated sebagai tim yang terlibat pada fase kajian karakteristik utama produk \& disain komponen teknis yang penting, fase proses manufaktur, dan terakhir fase penyusunan instruksi operasional $\&$ rencana pengendalian. 


\section{DAFTAR PUSTAKA}

Allandreyanto. (2018). Pemilihan Strategi Bersaing Sistem e-Commerce Produk Elektronik Pada PT. SID.

Barney, J.B. (1991). Firm Resources and Sustained Competitive Advantage, Journal of Management, 17 (1), 99-120.

Becerra, M. (2009).Business strategy. In Theory of the Firm for Strategic Management: Economic Value Analysis.Cambridge: Cambridge University Press, 141-173.

Bogdan, R. C. dan Biklen, K S (1982). Qualitative Research for Education: An Introduction to Theory and Methods. Boston London: Allyn and Bacon, Inc.

Creswell, J W. (1998). Qualitative Inquiry And Research Design: Choosing Among Five Traditions. London: SAGE Publications.

Cristiano, J.J., Liker, J.K. and White, C.C. III.(2001). Key factors in the successful application of quality function deployment (QFD), IEEE Transactions on Engineering Management, Vol. 48 No. 1, 81-95.

Daniari, Altami Nurmila. (2018). Rancangan Strategi Bisnis Perusahaan Agribisnis Peternakan Untuk Mencapai Sustainability.Studi Kasus: CV.XYZ.

Denzin, N. K., \& Lincoln, Y. S. (Eds.). (1994). Handbook of qualitative research. Sage Publications, Inc.

Fleisher, C and Bensoussan, B. (2002). Strategic and Competitive Analysis: Methods and Techniques for Analyzing Business Competition: Prentice Hall.

Franceschini, F. and Rossetto, S. (1998). Quality function deployment. How to improve its use. Total Quality Management. Vol. 9 No. 6, 491-500.

Guinta, L R., \& Praizler, N C. (1993). The Team Approach to Solving Problems and Satisfying Customers Through Quality Function Deployment. The QFD Book. New York: Amacom.

Grant, R M. (2016). Contemporary Strategy Analysis. John Wiley \& Sons, Ltd.

Hambrick, D. C. and Fredrickson, J.W. (2005). Are you sure you have a strategy?. Academy of Management Perspectives Vol. 19, No. 4. 
Hill, T. and Westbrook, R. (1997). SWOT analysis: It's time for a product recall. Long Range Planning, Vol. 30 No. 1, 46-52.

Jarzabkowski, P., Giulietti, M. and Oliveira, B. (2009). Building a Strategy Toolkit: Lessons from Business. London: Advanced Institute of Management Research.

Mehrjerdi,YZ. (2010). Applications and extensions of quality function deployment. Assembly Automation, Vol. 30 Issue: 4, 388-403.

Micro Flute Paper Report. (2019). Future Market Insight.

Porter, M. (1985). Competitive strategy. New York: Free Press.

Porter, M.E. (1996). What Is Strategy? Harvard Business Review, 74, 61-78.

Sugiyono. (2009). Memahami penelitian kualitatif. Bandung, CV Alfabeta.

Saaty,T.L. (1980). The Analytic Hierarchy Process. New York: McGraw-Hill.

Saaty,T.L. (1996). Decision Making with Dependence and Feedback: The Analytic Network Process. Pittsburgh: RWS Publications.

Sharma, J.R., Rawani, A.M. and Barahate, M. (2008). Quality function deployment: a comprehensive literature review. International Journal of Data Analysis Techniques and Strategies, Inderscience Enterprises Ltd, vol. 1(1), 78-103.

Yuksel İ, Dagdeviren M. (2007). Using the analytic network process (ANP) in a SWOT analysis - A case study for a textile firm. Inf Sci.177, 3364-3382.

Yin, R.K. (2014). Case Study Research: Design and Methods. California: Saga Publications Inc. $5^{\text {th }}$ ed

Zaim, S \& Şevkli, M. (2002). The methodology of quality function deployment with crisp and fuzzy approaches and an application in the Turkish shampoo industry. Journal of Economic and Social Research. 4, 27-32.

Zikmund, W.G., Babin, B. J., Carr, J., Griffin. C. (2009). Business Research Methods South-Western College Pub. $8^{\text {th }}$ ed. 